\title{
Parameters of Martensite Transformation and Structural State in Rapidly Quenched Ti35Ni15Cu Shape Memory Alloys
}

\author{
E. Cesari, J. van Humbeeck*, V. Kolomytsev**, V. Lobodyuk** and N. Matveeva*** \\ Universitat de les Illeas Balears, Palma-de-Malorka, Spain \\ * KUL, Leuven, Belgium \\ ** Institute of Metal Physics, Kiev, Ukraine \\ *** Institute of Metallurgy, Moscow, Russia
}

\begin{abstract}
Influence of the quenching rate on the martensite transformation parameters (transformation temperatures and hysteresis) of $50 \mathrm{Ti} 35 \mathrm{Ni} 15 \mathrm{Cu}$ shape memory ribbons obtained by meltspinning technique has been studied. Increase of quenching rate results in decrease of the $B 2 \Leftrightarrow B 19$ and $B 19 \Leftrightarrow \Rightarrow B^{\prime}$ ' martensile transformations temperatures, broadening of direct and reverse transformation intervals, decrease of hysteresis. The B2-type ordering takes place during rapid solidification. Rapid solidification of $50 \mathrm{Ti} 35 \mathrm{Ni} 15 \mathrm{Cu}$ alloy results in fine $\beta$-phase: grain size structure with relative large size scattering. Two types of martensi; morphology, plate-like and triangular shapes, have been observed in ribbons.
\end{abstract}

\section{INTRODUCTION}

Variation of the shape memory alloys chemical composition, preliminary plastic deformation, thermal and thermomechanical treatment is traditionally effective way to manage the martensite transformation parameters (namely, transformation temperatures and hysteresis), physical and mechanical properties caused by the martensite transformations.

Recently great attention is paid to development of relatively new casting technique as rapid quenching from liquid phase. High quenching temperature rates $\left(10^{4}-10^{7} \mathrm{~K} / \mathrm{s}\right)$ allow one to receive material with unusual structure - fine grain size or amorphous one - and changed mechanical properties [1-5]. In ribbons the martensite transformation temperature range is shifted with respect to one taking place in bulk material. Martensite plates have specific morphology. Mechanical properties are also changed as compared with those in bulk material. Large part of experimental data concerning study of rapidly quenched ribbon structure has been obtained on the TiNi-based SMA's in which $\mathrm{Cu}$ (up to 25 at.\%) was added instead of $\mathrm{Ni}$. There are several works related to study of the parent and martensite phases structure in rapidiy quenched TiNi-based alloys $[6,7]$.

So, from one hand, the TiNi-based SMA's are widely used in practice and the traditional schedule of the alloy casting, cold/hot working and thermal treatment are well developed but new properties and new application fields can be expected for non-conventional production technique - melt spinning or rapid solidification from liquid phase. From another hand, use of the melt spinning technology for SMA's production is not yet sufficiently studied and effect of the technology parameters (quenching rate, overheating above liquid solution temperature, ribbon thickness) on the parent and martensite phase structure, transformation temperatures and shape memory parameters is not well studied.

This work presents experimental results related to the effect of quenching temperature rate on the direct and reverse martensite transformation temperatures, transformation intervals and hysteresis, the parent phase and martensite microstructure of Ti35Ni15Cu meltspinning ribbons.

\section{MATERIAL AND TECHNIQUES}

Details of the meltspinning technique for ribbon production are presented elsewhere [1]. Short version of production technique specific for chosen Ti35Ni15Cu alloy is given below. Initial alloy ingot (50 $\mathrm{g}$ b; 
weight) was prepared by arc-melting technique in vacuum or inert gas atmosphere from iodide titanium (purity $99,8 \%$ ) and electrolytic nickel $(99.99 \%)$ and copper $(99.99 \%)$. To achieve good homogeneity the ingots were three-times remelt, ingot final chemical composition was $49.723 \mathrm{Ti}-35.258 \mathrm{Ni}-15.019 \mathrm{Cu}$ (at.\%) according to chemical analysis. Then ingot was cut in three parts, each part remelt in high frequency magnetic levitation inductor and put on outer side of rotated copper wheel (refrigerator). Quenching rate was varied from $10^{4}$ up to $10^{7} \mathrm{~K} / \mathrm{s}$ by changing the wheel angular speed. The thickness of ribbons was near 120 microns for $10^{4} \mathrm{~K} / \mathrm{s}, 60$ microns for $10^{5} \mathrm{~K} / \mathrm{s}$ and 35 microns for $10^{6} \mathrm{~K} / \mathrm{s}$.

Transformation temperatures were determined from the resistance versus temperature curves obtained by using special equipment. These measurements were performed in $77 \mathrm{~K}-800 \mathrm{~K}$ temperature range under continuously varying temperature regime with cooling rate $0.2-10 \mathrm{~K} / \mathrm{s}$ and heating rate 0.2 $20 \mathrm{~K} / \mathrm{s}$. Microstructure of high temperature $(\beta, \mathrm{bcc})$ phase and martensite phases was studied by means of metallography (MIM-8) and transmission electron microscopy (Tesla).

\section{EXPERIMENTAL RESULTS AND DISCUSSION}

The resistance versus temperature curves for $50 \mathrm{Ti} 35 \mathrm{Ni} 15 \mathrm{Cu}$ melt spinning ribbons are shown in fig. 1 for quenching rates $10^{4} \mathrm{~K} / \mathrm{s}$ (a), $10^{5} \mathrm{~K} / \mathrm{s}$ (b) and $10^{6} \mathrm{~K} / \mathrm{s}$ (c), respectively. Two regions of the resistances anomaly associated with two martensite transformations are observed: $B 2=B 19\left(M_{s 1}-M_{f 1}\right)$ and $B 19 \Rightarrow B 19^{\prime}\left(M_{s 2}-M_{f 2}\right)$ on cooling and reverse sequence $B 19^{\prime}=>B 19\left(A_{s 2}-A_{f 2}\right)$ and $B 19=>B 2\left(A_{s 1}-A_{f 1}\right)$ on heating. These two transformations are separated by definite temperature interval that becomes narrower with increase of quenching temperature rate. It is seen that transformation temperatures also shift to lower temperatures. Hysteresis of martensite transformations measured as a temperature interval between $50 \%$ of new phase formation also changes specifically. Variations of these parameters are presented in fig. 2 and 3. Hysteresis of the $\mathrm{B} 2 \Leftrightarrow \mathrm{B} 19$ transformation remains near $12 \mathrm{~K}$ for temperature rates $10^{4}-10^{5} \mathrm{~K} / \mathrm{s}$ and decreases a little for $10^{6} \mathrm{~K} / \mathrm{s}$, while hysteresis of the $\mathrm{B} 19 \Leftrightarrow \mathrm{B} 19^{\prime}$ transformation decreases significantiy from $16 \mathrm{~K}$ to $6 \mathrm{~K}$ in $10^{4}-10^{5} \mathrm{~K} / \mathrm{s}$ temperature rate interval and only small variation occurs at higher temperature rates. This difference in hysteresis behaviour for two transformations may be caused by difference in the martesite phases microstructure, crystal size and "perfectness" of the martensite/martensite boundaries.

$$
\mathrm{B} 2<\Rightarrow \mathrm{B} 19
$$

Table 1.

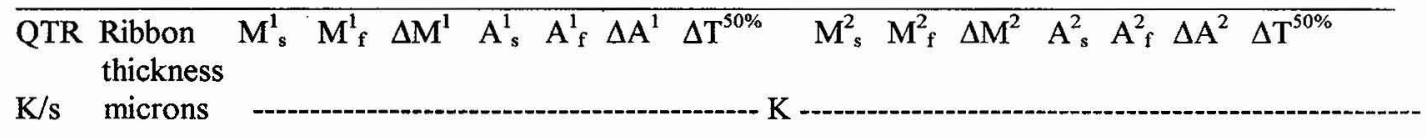

$\begin{array}{rrrrrrrrrrrrrrrr}10^{4} & 115 & 336 & 308 & 28 & 328 & 348 & 20 & 12 & 235 & 189 & 46 & 187 & 247 & 54 & 16 \\ 10^{5} & 40 & 326 & 304 & 22 & 325 & 353 & 28 & 13 & 208 & 148 & 60 & 148 & 213 & 65 & 6 \\ 10^{6} & 35 & 319 & 280 & 39 & 293 & 329 & 36 & 10 & 198 & 153 & 45 & 163 & 213 & 50 & 4\end{array}$

There exists also a difference in variation of the $\mathrm{B} 2 \Leftrightarrow \mathrm{B} 19$ and $\mathrm{B} 19<=\mathrm{B} 19^{\prime}$ martensit: transformation temperatures with increase of temperature rate from $10^{4}$ to $10^{6} \mathrm{~K} / \mathrm{s}$ (see fig. 3 and Table 1). Qualitative explanation of this effect can be given taking into account different nature of the "initial conditions": the first occurs from parent $\beta$ phase containing thermal stresses while second is the martensite-martensite transformation from state with high defect density.

Let us consider regularity of ribbon microstructure formation at different temperature rates. Metallography measurements showed fine grain size of the $\beta$ phase and its considerable scattering with 
increase of temperature rate. Dispersion in grain size can results in widening of the direct and reverse transformation temperature ranges, namely $\mathrm{M}_{\mathrm{s}}-\mathrm{M}_{\mathrm{f}}$ and $\mathrm{A}_{\mathrm{s}}-\mathrm{A}_{\mathrm{f}}$ intervals.

Both small grain size and its dispersion are confirmed by the TEM/SAD studies. Relatively large grains (>10 microns) are observed in ribbons prepared with temperature rate $10^{4} \mathrm{~K} / \mathrm{s}$. SAD patterns taking in such grains are typical single crystal set (see $\mathrm{SAD}$ in fig. $4 \mathrm{a}$, foil orientation [011 $]_{\beta}$ ). Despite high quenching temperature rates the B2-type ordering took place in $\beta$ phase. Indeed, SAD patterns contain $\{100\}_{\beta},\{111\}_{\beta}$ and others superstructure reflections.

Decrease of the $\beta$ phase grain size with quenching rate results in specific changes of SAD patterns there appear diffraction circles in addition to definite point reflection sets. Finally diffraction circles become continued and radial spread (fig. $4 \mathrm{~b}$ ) at temperature rate near $10^{6} \mathrm{~K} / \mathrm{s}$. Possible reasons of such diffraction circles broadening are high thermal stresses level in thin ribbons and geometrical effect for grain size less than 1 micron.

Several general features were found with effect of quenching temperature rate on the martensite phase microstructure formed during rapid solidification or during cooling ribbon to lower temperatures.

Usually the thermoelastic martensite in TiNi based SMA's has plate-like morphology and linear size of plates is varied with temperature or stress applied. Rate of martensite plate size change is a function of overcooling degree below Ms, cooling/heating rate and stress level.

Alloying of TiNi by $\mathrm{Cu}$ leads to significant change in the martensite morphology. In addition to plate-like martensite there appears areas with triangle morphology (fig. 5). Volume ratio between two) types morphologies depends on quenching temperature rates. For low temperate rates $\left(10^{4} \mathrm{~K} / \mathrm{s}\right)$ the dominant martensite crystal morphology is triangular shaped one. For temperature rates near $10^{5} \mathrm{~K} / \mathrm{s}$ volume ratio between plate-like and triangle-shaped morphologies becomes close to $1: 1$. For higher quenching rate $\left(10^{6} \mathrm{~K} / \mathrm{s}\right)$ the predominant martensite crystal morphology is plate-like one but size of plates becomes smaller.

Attempt to find correspondence between two B2< $=>B 19$ and $\mathrm{B} 19<=>\mathrm{B} 19^{\prime}$ martensite transformations and two types of martensite morphology in $\mathrm{Ti} 35 \mathrm{Ni} 15 \mathrm{Cu}$ alloy does not give positive result.

\section{CONCLUSIONS}

1. Influence of the quenching rate on the martensite transformation parameters (transformation temperatures and hysteresis) of $50 \mathrm{Ti} 35 \mathrm{Ni} 15 \mathrm{Cu}$ shape memory ribbons obtained by meltspinning technique has been studied. Increase of quenching rate results in decrease of the B2<=>B19 and B19<=>B19' martensite transformations temperatures, broadening of direct and reverse transformation intervals, decrease of their hysteresis.

2. Despite high quenching rates the B2-type ordering takes place during rapid solidification.

3. Rapid solidification of $50 \mathrm{Ti} 35 \mathrm{Ni} 15 \mathrm{Cu}$ alloy results in fine $\beta$-phase grain size structure with relative large size scattering.

4. Two types of martensite morphology, namely plate-like and triangular shapes, have been observed in rapidly quenched $50 \mathrm{Ti} 35 \mathrm{Ni} 15 \mathrm{Cu}$ shape memory ribbons.

\section{Acknowledgments}

Authors are very appreciate to the INCO-Copernicus project IC15-CT96-0704 (DG 12-MUYS) and the Science\&Technology Center in the Ukraine project STCU-453 for financial support. 


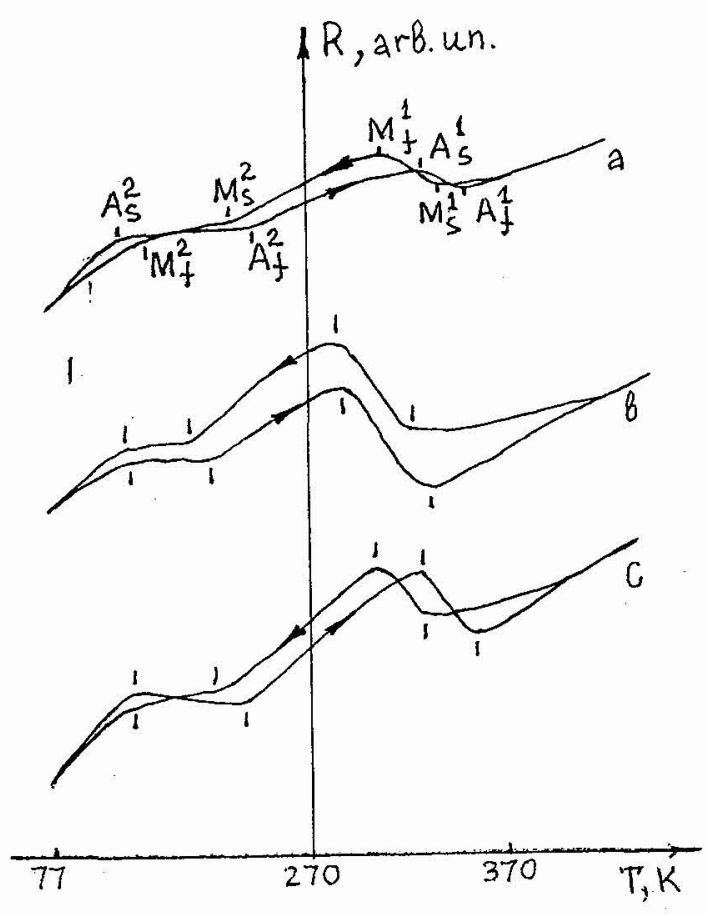

Figure 1: Electrical resistance versus temperature dependencies: $10^{4} \mathrm{~K} / \mathrm{s}$ (a), $10^{5} \mathrm{~K} / \mathrm{s}$ (b), $10^{6} \mathrm{~K} / \mathrm{s}$ (c).

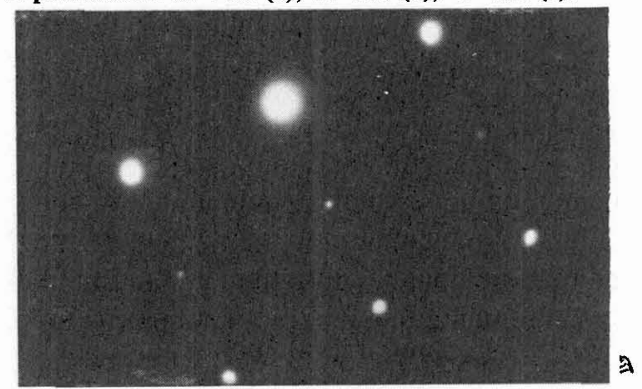

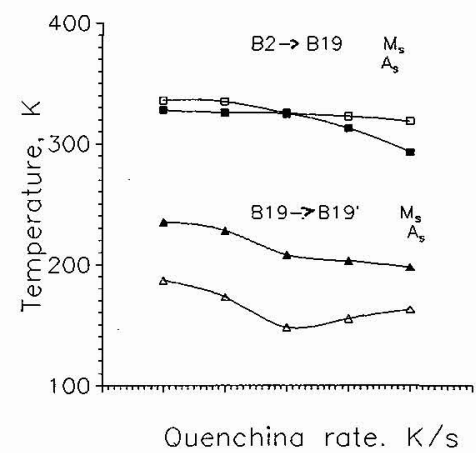

Figure 2: Transformation temperatures versus quenching rate for $\mathrm{B} 2 \Leftrightarrow \Rightarrow \mathrm{B} 19$ and $\mathrm{B} 19 \Leftrightarrow \mathrm{B} 19^{\circ}$

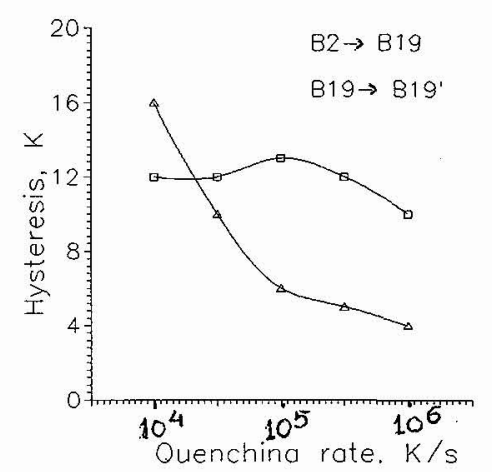

Figure 3: Hysteresis variation with quenching rate for

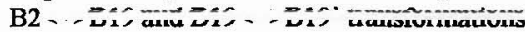

b

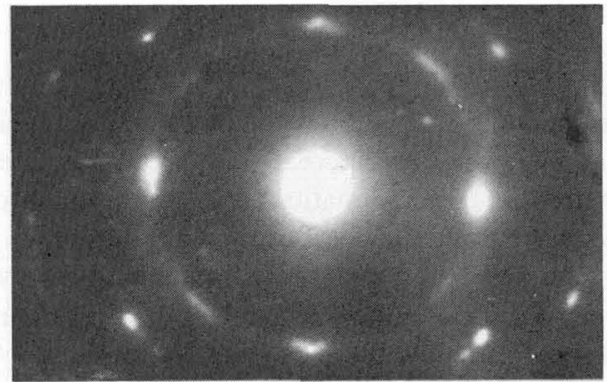

Figure 4: Two types of $S A D$ patterns: $10^{4} \mathrm{~K} / \mathrm{s}(\mathrm{a}), 10^{5} \mathrm{~K} / \mathrm{s}(\mathrm{b})$.

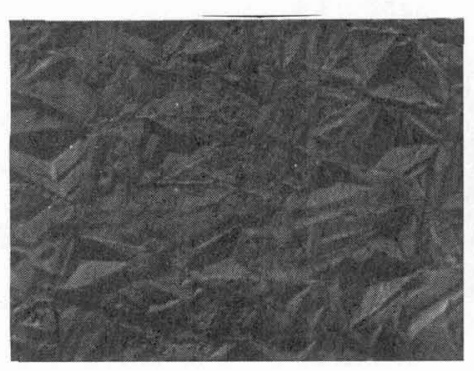

a

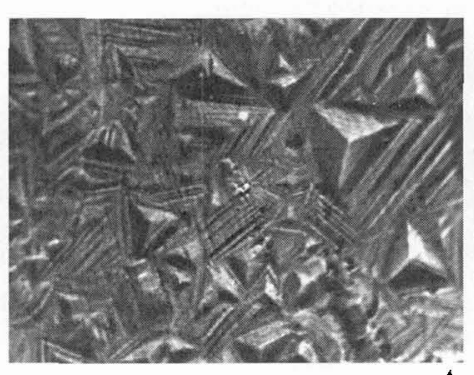

b

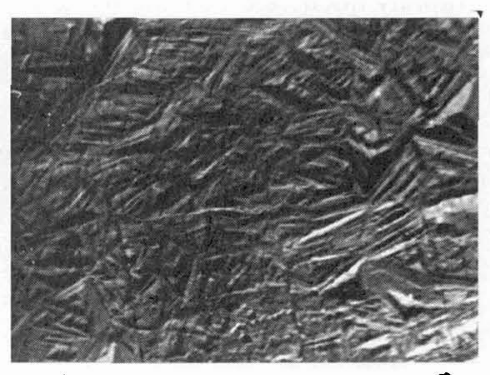

c

Figure 5: Plate and triangular martensite morphology for $10^{4} \mathrm{~K} / \mathrm{s}(\mathrm{a}), 10^{5} \mathrm{~K} / \mathrm{s}$ (b) and $10^{5} \mathrm{~K} / \mathrm{s}$ (c). $x 500$. 


\section{References}

[1] Matveeva N.M., Kovnerystii Yu.K., Matlakhova L.A., Friedman Z.G., Lobsov N.A., Izvestiya Academy of Sciences USSR, Metals, 4 (1987) 97-100.

[2] Matveeva N.M., Kovnerystii Yu.K., Bykovskii Yu.A., Shelyakov A.V., Kostyanaya O.V. Izvestiya Academy of Sciences USSR, Metals, 4 (1989) 171-175.

[3] Matveeva N.M., Lobodyuk V.A., Kolomytsev V.I., Lovzova I.D., Izvestiya Academy of Sciences USSR, Metals, 3 (1991) 164-168.

[4] Babanly M.B., Lobodyuk V.A., Matveeva N.M., "Peculiarities of martensite transformations in rapidly quenched 50Ti(50-x)NixCu alloys", Proc.Martensite-91, Kiev, 1992, 338-341.

[5] Babanly M.B., Lobodyuk V.A., Matveeva N.M., Izvestiya Academy of Sciences USSR, Metals, 5 (1993) 171-177.

[6] Euken S., Hornbogen E., "On martensite temperatures of rapidly quenched shape memory alloys", ICOMAT-86, 780-785.

[7] Mizin S.V., Novikov A.I., Fattkulina L.P., Fizika metallov I materialovedenie, 9 (1990) 150-157. 